\title{
Application of Set Theory Formulas in the Presentation of Lexical Meronymy Benard Odoyo Okal ${ }^{1}$, Frida Akinyi Miruka ${ }^{2}$ \\ ${ }^{1}$ Assistant Lecturer \& PhD candidate, Department of Kiswahili, Maseno University, Kenya \\ ${ }^{2} \mathrm{PhD}$ candidate, Department of Languages, Linguistics \& Literature, JOOUST, Kenya
}

\section{*Corresponding Author:}

Benard Odoyo Okal

Email: benardodoyo@yahoo.com

\begin{abstract}
Lexemes relate in terms of sense in various ways that are linguistically referred to as homonymy, polysemy, antonymy, synonymy and even hyponymy among others. Though some of these relations like hyponymy tend to include majorly lexemes referring to discrete objects that relate in terms of sense, there is a lexical relation whereby one whole object refers to a combination of various parts which may include discrete and abstract entities. These parts are of different structures and functions. This relation involving the whole and the parts is normally referred to as meronymy. Thus the article shows the application of set theory formulas in the presentation of lexical meronymy. Though there are component - integral object, member - collection, portion - mass, stuff - object, feature - activity and also place - area relations in meronymy, the study has only embarked on the component - integral object and place -area relations together with some two more proposed period - time and colour - spectrum relations.
\end{abstract}

Keywords: sense, meronymy, holonym, canonical, facultative

\section{INTRODUCTION}

Lexemes that form part of vocabularies of given languages always tend to relate just as humans beings do. These vocabularies are normally structured in such a way that they have internal organization that helps in giving their full meanings in a linguistic system [1]. The internal organization gives rise to many relationships amongst lexemes. Thus, the linguistic intelligentsia came up with various terminologies to refer to these relationships such as homonymy, polysemy, antonymy, synonymy, hyponymy and meronymy or partonymy $[2$, $3,4,5,6]$. These relations grouped together are normally referred to as sense relations meaning a set or relation that holds between words in which words acquire meanings in comparison with others in the same language [2].

Though there are numerous sense relations in languages, this work focuses only on one type of relation called meronymy. Meronymy is composed of a Greek word 'meros' meaning 'part' [7] and also the bound morpheme $\{-n y m y\}$ used to describe any sense relation between words [8]. Therefore, meronymy refers to a relation denoting parts and the corresponding whole [3] or a relation between a body and its parts or partwhole relation [9]. Meronymy or partonymy is a sense relation of inclusion just like hyponymy. However, as hyponymy refers to a relation between hypernym (superordinate) and the lower term hyponym with a formula 'words of the same kind' [10] or 'kind of' [5], meronymy tends to take a formula like ' $X$ is part of $Y$ ' or ' $Y$ has $X$ ' [3]. For instance, human body has parts such as head, neck, hands, trunk and legs or the head, neck, hands, trunk and legs are parts of the body.

The use of 'part of' and 'has' are normally arrived at depending on the approaches used to define meronymy. According to [11], top-down approach results into whole-part definition that requires words such as 'has part' or 'consists of'. On the other hand, the bottom-up approach results into part-whole definition with the words 'is part of'. Besides the use of 'part of' and 'has', other terminologies used are component, member, portion and feature. In meronymy, the whole body is linguistically referred to as a holonym and the parts that relate to it are basically called meronyms or partonyms $[3,11,1]$. If many meronyms form a holonym then terminologies such as comeronyms or co-partonyms are used. For instance, the head and the neck are co-meronyms of a holonym body.

Generally, parts or meronyms have various characteristic features such as: autonomy or independence, have non-arbitrary boundaries and also clearly defined roles or functions that tend to support the other parts in relation to the whole [3]. Therefore, parts are somehow independent in various ways, the boundaries are not clearly defined in some bodies but can be detached at a joint, and these parts have functions that help the whole body functioning. Partitioning of these sections of a whole will definately depend on the researcher or are culturally bound. Though hyponymy structures concepts hierarchically according to logical aspects, according to Khoo and Na 
as cited in [11], meronymy tends to reflect a physical point of view. Thus meronymy is a sense relation of nouns denoting physical objects or parts. However this article agrees with the notion of [3] that meronymy should not be limited to physical or concrete objects only but also witnessed amongst non-concrete entities like events, actions, processes, states and other abstract nominal notions. Thus the work has also studied the abstract notions confined to parts of time and the components of colour which we are unable to touch.

According to [3], meronymy exhibits the following characteristics: firstly, lexemes representing parts generally belong to the same word category. That is to say that if the body is a noun then the parts of this body must also be nouns. Secondly, meronymy relation is not natural and does not involve natural taxonomies. Therefore, division of body parts and naming will always depend on the speaker or the researcher and therefore culture-bound. Thirdly, meronymy has very fuzzy subdivisions on body parts. Researchers therefore normally come up with different classifications even on the same body under study. Fourthly, since specialized discourses tend to structure the world differently and members of particular speech community tend to share a common understanding of a disciplinary vocabulary [1], speakers of a language therefore tend to form meronymy sense relations at the word level according to cognitive and mental abilities, and also the outside world experience [12].

The main aim of this paper is to analyze lexically nominal meronymy. The paper is therefore guided by the following objectives:

i. To identify nominal meronymy from a lexicographical material.

ii. To classify lexical meronymy into various sub relations.

iii. To present the lexical meronymy by using set theory formulas.

The scope of this study includes meronyms of human body in which parts such as the hand, head, leg, neck, trunk and the internal parts are analyzed. The body parts of fish, bird, animal, plant, house, vessel, the world, parts of other objects, parts of time and parts of colour are also studied. The study involves a formulaic presentation of meronymy by using the mathematical principles borrowed from the set theory symbols. The outcome of this study is believed to provide a good text for the studies of lexical semantics and also contributes to the studies of mathematical linguistics.

The paper is guided by Componential Analysis theory. Componential Analysis theory refers to a method whereby the meaning of a general lexeme is decomposed into smaller lexemes with related meanings [13, 14]. These smaller lexemes have distinctive features indicated in a table matrix and involves the use of two signs $[+,-][13,14]$. The [+] sign shows the presence of a feature and the [-] shows the absence of a feature under consideration $[15,16]$. The theory was founded by Jost Trier in 1934 in an attempt to classify lexemes into their semantic fields that was later named as the Semantic Field Theory [17]. The theory was later developed by [18], [19], [20], and $[15,16]$. Though Componential Analysis is an old theory, many lexical semanticists regard it as a more practical and analytical as opposed to others like Core Meanings theory, Frames theory and Prototype theory. The Componential Analysis theory has been used in this work to show the distinctive features of the parts of the whole.

\section{METHODOLOGY}

The study embraced an integrated design including both the descriptive and analytical designs. The study was basically library based whereby relevant materials concerning meronymies were observed. Since this is a lexical study, many materials on semantics were studied. Relevant data was purposively sampled whereby the lexemes that show parts of the body both animate and inanimate were identified from a dictionary and recorded. The identification of meronymy was done by the use of the pattern-based approach as proposed by Girju et al as cited in [21] in which they proposed formulas such as $\mathrm{NP}_{\text {mero }}$ is part of $\mathrm{NP}_{\text {holo }}$ or $\mathrm{NP}_{\text {holo }}$ has $\mathrm{NP}_{\text {mero }}$ among others. NP means noun phrase, mero means meronym and holo means holonym. This approach is basically used to view syntactic patterns of lexemes that tend to support the formulas above thus enables the researcher to identify which lexeme is a holonym and which one is a meronym. These formulas are shown as in the examples below:
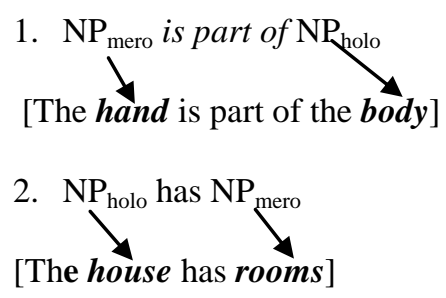

In example 1, the hand is identified from the sentence as a meronym of a holonym called body. In example 2, a holonym house has the rooms that are identified as meronyms. These kinds of patterns are many in various lexicographical materials.

The selected lexemes were purposively classified into various themes that include body parts of human, fish, bird, animal, plant, house, vessel, the world, other objects, parts of time and colour. The body parts were analyzed in a matrix table to show their distinctive features using the feature based Componential Analysis theory. In each theme, the lexemes of the major parts of a holonym were presented using the set theory formula of $\{\mathrm{Y}\} \exists\{\mathrm{X}\}$. In the set theory, one set contains other 
sub sets or other related elements [22]. These elements may be humans, things, symbols and even numbers [23]. The elements in a set are normally arranged following a particular pattern and these elements generally have specific features [24]. The common pattern is that whereby the elements are arranged from the first to the last and separated from each other by the use of a comma [23]. For example, colour is a set of $\{$ red, black, white... \}. In many occasions, the set theory is used in mathematics, linguistics and also philosophy [22]. However, in the linguistic field, the theory is applicable in the analysis of the sub sets of a sentence [25] or even the lexical sense relations, meronymy being one of them.

Though, the theory is basically used in mathematical practices, it can also be used in linguistics $[22,3]$. Generally, the presentation of set theory depends on the epsilon symbol [26, 27, 28, 24, 29]. The epsilon symbol $(\exists, \in)$ is basically derived from Greek word that means containing or an element of [30]. The epsilon symbol exhibits two faces indicating two directions hence posing two different meanings. These are: $(\exists)$ means contains or includes and the $(\in)$ means an element of. When dealing with meronymy then the set theory formula would therefore mean that $\{\mathrm{Y}\}$ is a holonym, $\{\mathrm{X}\}$ is a meronym and the epsilon [ $[\exists]$ means contains. Thus we may use $\{Y\} \ni\{X\}$ meaning set $\{Y\}$ contains set $\{X\}$. On the other hand, if we have $\{X\} \in$ $\{Y\}$ then we mean that set $\{X\}$ is an element of set $\{Y\}$. The elements to be contained in the main set may be of whichever number. Though the epsilon [ $\ni$ ] symbol generally refers to the term 'contains', there are instances when it would also mean "consist of" as was proposed by [11] when defining meronymy from the top-down approach. In this regard, 'contains' and 'consists of' are likely to be considered synonymous or rather interchangeable in the meronymy studies.

\section{RESULTS AND DISCUSSIONS}

Meronymy sense relation tends to be complex because there seems to be no single classification instead there are several relations with own semantic properties [31]. For example, [3] classifies meronymy into relations based on quantificational differences such as class - member, collection - member, object material, and substance - particle. However, this work majorly relied on the psycholinguistic classification of meronymy into six types of relations as propounded by [7] that include: the component - integral object, member - collection, portion - mass, stuff - object, feature - activity, and also place - area.

The component - integral object relation includes for instance the pedal - bicycle or handle cup. The relation deals with a whole body of something made of either necessary or optional parts essential for the proper functioning of the whole even though they are homeomerous. These parts have different structures of varied shapes. The relation is generally analyzed by looking into features such as function, homeomerous and separability, and additional features deemed necessary by the researcher in order to give a true picture of any complex whole. The main pillar of this relation is that the object is divided into the patterned structural components. The member - collection relation includes for example ship - fleet or tree forest. In this relation, a member is not supposed to perfom any function or even posses any patterned structure in relation to themselves and also to the whole but forms part of the collection.

The portion - mass relation includes examples such as slice - pie or grain - salt. The relation means that a portion under the study has parts that are similar to each other and also to the whole that is basically referred to as the mass. The stuff - object relation has examples such as steel - car or steel - bike. This relation talks of what an object is made of. It refers to a constituency of things. It is normally expressed by the use of the term 'is partly'. The feature -activity relation talks about cases like paying - shopping or dating adolescence. The relation refers to designated features or phases of activities and processes. The relation is normally referred to by the use of 'part'. For instance, 'paying' is part of 'shopping'. This relation seems to be more concerned with meronymy of verbs. The place area relation involves examples like oasis - desert. In this relation, [7] indicate that places are not just parts by virtue of functionality in respect to the holonym but every place tends to be homeomerous or similar to every other. The main pillar is that the places cannot be separated from the areas in which they are part of.

Though there are six main types of classification of meronymy relations according to [7], the work has only used two of these types, the component - integral object and the place - area. The study realized that the six types of meronymy relations seem to work well with parts of physical objects but fail to accommodate parts of time and colour which are abstract. For instance, morning is referred to as 'the part of the day from the time when people wake up until midday or before lunch' [30: 960]. From this example, morning is therefore part of the day which is of a specific time. In this regard, the paper therefore proposes a classification called period - time relation to cater for this case. This is because period is 'a particular length of time' [30:1089] and time is 'what is measured in minutes, hours, days etc' [30: 1564]. Thus, morning has a length of time, when people wake up until midday.

Another proposed meronymy relation is the colour - spectrum relation. Colour is 'the appearance that things have that results from the way in which they reflect light' [30:280]. Spectrum is 'band of coloured lights in order of their wavelengths' [30:1430]. Thus spectrum tends to mean all colours put together to form 
a body like that of a rainbow. Therefore, the paper is premised on four relations of meronymy: the component - integral object and place - area from [7], and the period - time and colour - spectrum relations as proposed by the researchers.

[7] explain that the parts of a body should be viewed by considering some three distinctive features such as functional (part has a function with respect to the whole in their spatial and temporal locations), homeomerous (part is identical to the other parts making up the whole and also identical to the whole) and separable (part can be detached from the whole). The distinctive feature of separability means that it must be from a designated joint or else if a whole is cut from any point then we get what [3] termed as pieces and therefore not parts. In considering these three distinctive features together with the others as shall be determined by the researchers, the $[+,-]$ signs are used in a table matrix.

The results are presented using the set theory formula of $\{\mathrm{Y}\} \ni\{\mathrm{X}\}$. The study borrowed some lexical semantics terminologies such as canonical meronym and facultative meronym from [3] in order to address its concerns. Canonical means necessary for example the head is a canonical meronym of the holonym body. Facultative means optional for example the door is a facultative meronym of a house. In this work, the facultative meronyms are indicated by an asterisk $(*)$. The sections below begin with the presentation of the component - integral object relation in meronymy studies.

\section{Component - Integral Object Relation}

According to [7], the component - integral object relation generally tends to have distinctive features such as [+functional, -homeomerous, +separable]. In this study, the component - integral object relation analyzed includes parts of human body, fish, bird, animal, plant, house, a vessel and also parts of other selected objects:

\section{Human body parts}

Human body comprises different parts of varied sizes and shapes. These parts are independent, structurally patterned, and closely and functionally interdependent. According to [30], a body is semantically referred to as the whole physical structure of either the human being or the animal. However, the term may also be extended to the physical description of the structures of other creatures like fish, reptiles, amphibians and also inanimate beings. For example, we may have a body of a table among others. This definition of the body relies on the outward physical appearance. Thus, the human body $\ni$ \{head, neck, hands, trunk, legs $\}$ and these parts are basically regarded as canonical co-meronyms. These five key human body parts exhibit the following distinctive features as shown in table $\mathbf{1}$ below:

Table 1: Distinctive features of the human body parts

\begin{tabular}{|l|l|l|l|l|l|}
\hline & head & neck & hands & trunk & legs \\
\hline Functional & + & + & + & + & + \\
\hline Homeomerous & - & - & - & - & - \\
\hline Separable & + & + & + & + & + \\
\hline Top that contains eyes, nose, ears and mouth & + & - & - & - & - \\
\hline Exists between head and trunk & - & + & - & - & - \\
\hline Hang on the sides of the trunk and has fingers & - & - & + & - & - \\
\hline Main part supporting the neck, hands and legs & - & - & - & + & - \\
\hline Long part connecting the feet and the trunk & - & - & - & - & + \\
\hline
\end{tabular}

From the above table 1, all body parts have the same feature [+functional, -homeomerous, +separable]. These parts are [-] homeomerous because they are not identical in structure, both shape and length as compared to the whole. However, each part has various distinctive features. The head has [+top that contains eyes, nose, ears and mouth], neck [+exists between head and trunk], hands [+hang on the sides of the trunk and has fingers], trunk [+main part supporting the neck, hands and legs] and legs have [+long part connecting the feet and the trunk].
It is also evident that the human body does not just contain elements or single parts but rather includes sub parts or sub sets which have also other specific sub parts. In this sense, we are therefore forced to apply another set theory formula whereby one bigger set includes other sub sets with various elements. The formula is indicated as $[\{A\} \subseteq\{\mathbf{B}\}][22,28]$. In this case, $\{A\}$ is a sub set of set $\{B\}$. We have to note that many sub sets can be included in one bigger set. In this regard, the sets of the human body may therefore be presented as follows:

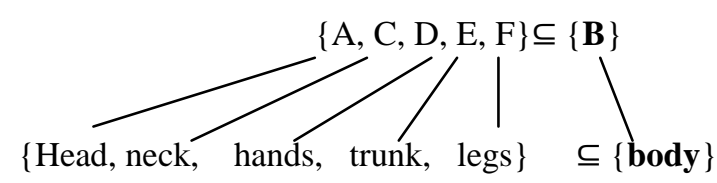


The hand is part of the body that stretches from the shoulder and hangs outwardly. A normal human body has two hands, one on the left and the other on the right side. Every complete hand has the following canonical parts presented as:

Hand $\ni\{$ arm, arm pit, elbow, fingers, fore arm, palm, wrist . Fingers $\exists$ \{fore finger, little finger, middle finger, ring finger, thumb

Head $\ni$ \{back of the head, baldness*, brain, central part of head, ears, eyes, face, forehead, hair, mouth, nose, nasal passage, scalp, skull

Ears $\ni$ \{auditory bones, cochlea, ear canal, ear drum, ear lobe, ear hole, Eustachian tube, mastoid, outer ear ring, semicircular canals

Eyes $\ni$ \{cornea, corner of the eye, eye brows, eye lashes, eye lids, eye sockets, iris, pupil/eye ball $\}$

Face $\ni$ \{chin, fore head, cheeks, beards*, goatee*, jaw, moustache*, whisker*\}

Mouth $\ni$ \{gap*, gum, lips, oral cavity, palate/velar, teeth, tongue

Nose $\ni$ \{nasal cavity, nostrils

Skull $\ni\{$ anterior cortex/Broca's area, arcuate fasciculus, cerebral hemispheres, corpus callosum, cortex/gray matter, frontal lobe, left hemisphere, mortor cortex, occipital lobe, parietal lobe, posterior cortex/Wernicke's area, right hemisphere, temporal lobe, white matter

Leg $\ni$ \{ankle, buttocks, foot, heel, hip, knee, knee cap, knuckle, outer thigh, sole/foot print, thigh, toes $\}$

Neck $\ni$ \{epiglottis, gland, glottis, glottal cords, larynx, nape, throat $\}$

Trunk $\ni$ \{abdomen, back, breasts, chest, chest hair*, groin, nipple, shoulders, shoulder tip, spinal cord, waist $\}$. Groin $\ni$ anus, cervix, clitoris, hymen, penis, placenta, prepuce/foreskin, pubic area, pubic hair*, scrotum/testicles, vagina, vulva/perineum\}

The internal parts of the human body are not visible from outside. These parts can therefore be referred to as internal body parts. These parts are interrelated in performing various functions within the human body. Though the parts have different shapes, there are others that are regarded as very functionally distinct thus referred to as organs like the heart, lungs and even the kidney. An organ is part of the body with a particular distinct function [30]. Internal body parts and organs include the following:

Internal body parts $\ni$ \{bones, diaphragm, internal organs, muscle, nerve $\}$

Bones $\ni$ \{cheek bone, coccyx, collar bone, collar depression, fore arm bone, hollow bone, humerus, jaws, neck bone, pelvic bone, ribs, shin bone, thigh bone, tip of the bone, vertebrae, waist bone

Internal body organs $\ni$ \{appendix, belly, bladder, bowel/anus, colon, duodenum, entrails, gall bladder, heart, kidney, large intestines, liver, lungs, pancreas, rectum, small intestines, stomach, spleen and the womb/uterus \}

Nerve $\ni\{$ aorta, artery, capillary, jugular vein, navel, placenta, umbilical cord, vein $\}$

\section{Parts of fish}

Parts of fish are not generally so much different from the human body parts except in just a few sections. The scales with an asterisk indicate that not all fishes have them. However, generally, the description of fish normally includes scales, fins and even the tail. The body of fish $\ni$ \{head, trunk, tail $\}$ with the following distinctive features as illustrated in the table below:

Table 2: Distinctive features of body parts of fish

\begin{tabular}{|l|l|l|l|}
\hline & head & trunk & tail \\
\hline Functional & + & + & + \\
\hline Homeomerous & - & - & - \\
\hline Separable & + & + & + \\
\hline Part that contains eyes, nostrils, earholes, mouth, gills & + & - & - \\
\hline Main body that has fins and connects the head and tail & - & + & - \\
\hline Part that sticks out and moves at the back of the body & - & - & + \\
\hline
\end{tabular}

The table shows that these body parts of fish posses the following distinctive features: head [+ part that contains eyes, nostril, earhole, mouth and gills], trunk [+ main body that has fins and connects the head and tail] and tail [+ part that sticks out and moves at the back of the body]. These parts have common features such as [+functional, -homeomerous, + separable]. The head of fish contains two eyes, gills, mouth, nostrils and the trunk that may have scales* as facultative part and also the side fins ${ }^{*}$ specifically used for swimming. In general: 
Head $\ni$ \{eyes, gills, mouth, nostrils, scales*, side fins*\}

\section{Parts of a bird}

Basically, body parts of a bird almost resemble that of humans except that as humans have hands birds have wings and as we have coccyx the birds have tail. The body of the bird $\ni$ \{head, neck, trunk, wings, legs, tail\} which are canonical and have the following distinctive features:

Table 3: Distinctive features of body parts of the bird

\begin{tabular}{|l|l|l|l|l|l|l|}
\hline & head & neck & trunk & wings & legs & tail \\
\hline Functional & + & + & + & + & + & + \\
\hline Homeomerous & - & - & - & - & - & - \\
\hline Separable & + & + & + & + & + & + \\
\hline Top part containing eyes, nostril, earhole, beak & + & - & - & - & - & - \\
\hline Exists between head and trunk & - & + & - & - & - & - \\
\hline Main part supporting the neck, wings and legs & - & - & + & - & - & - \\
\hline Attached to the sides of trunk and has feathers & - & - & - & + & - & - \\
\hline Long part connecting the feet and the trunk & - & - & - & - & + & - \\
\hline Part attached to the posterior end of the trunk & - & - & - & - & - & + \\
\hline
\end{tabular}

From the table 3 above, it is evident that the animal's body parts have common features such as [+ functional, -homeomerous, +separable]. However, the following distinctive features are witnessed: head [+top part containing eyes, nostril, earhole, beak], neck [+exists between head and trunk], trunk [+main part supporting the neck, wings and legs], wings [+attached to the sides of trunk and has feathers], legs [+long part connecting the feet and the trunk] and tail [+part attached to the posterior end of the trunk].

Bird's head $\ni$ \{beak, cock's comb*, earholes, eyes, nostrils, tongue, tuft of hair*\}

Bird's leg $\ni$ \{bid's spur, cock's spur, toes

Bird's tail $\ni$ \{feathers, long tail feather*\}

Bird's trunk $\ni$ \{legs, wings, wing bones]

Birds also have internal organs that are not far much different from those of humans except in sizes and shapes.
These internal organs have various functions for efficient body coordination of the bird. Therefore, in general, these organs include:

Bird's internal organs $\ni\{$ bile, cloaca, gizzard, heart, intestines, liver, lungs $\}$

\section{Parts of an animal}

Animal's body parts are not generally different from the human's. The whole body of animal is covered with the skin. There are the outer and the inner parts of an animal with varied shapes, sizes and functions but closely interdependent. The outer sections of the animal body $\ni\{$ head, neck, trunk, legs, tail $\}$ which are canonical and have the following distinctive features:

Table 4: Distinctive features of body parts of an animal

\begin{tabular}{|c|c|c|c|c|c|}
\hline & head & neck & trunk & legs & tail \\
\hline Functional & + & + & + & + & + \\
\hline Homeomerous & - & - & - & - & - \\
\hline Separable & + & + & + & + & + \\
\hline Top part containing eyes, nose, ears and mouth & + & - & - & - & - \\
\hline Exists between head and trunk & - & + & - & - & - \\
\hline Main part supporting the neck and legs & - & - & + & - & - \\
\hline Attached to the trunk for locomotion & - & - & - & + & - \\
\hline Attached to the posterior end of the trunk & - & - & - & - & + \\
\hline
\end{tabular}

From the table above, it is evident that the bird's body parts have the following distinctive features: head [+top part containing eyes, nose, ears and mouth], neck [+ exists between head and trunk], trunk [+ main part supporting the neck and legs], legs [+attached to the trunk for locomotion] and tail [+ attached to the posterior end of the trunk]. However, these parts have common features like: [+functional, -homeomerous, + separable].
The head of an animal has a variety of parts both canonical and facultative such as:

Animal's head $\ni$ \{eyes, ears, horns*, mouth, nose

Animal's horn* $\ni\{$ big animal horn, big horn, elephant tusk, rhino horn, small animal horn, small elephant tusk\} 
Animal's mouth $\ni$ \{gum, hard palate, soft palate, teeth, tongue $\}$

Animal's neck $\ni$ \{cows dewlap*, mane* and the sheep's dewlap*\}

Animal's leg $\ni$ \{animal's foot, cow's legs, hooves*, ox foot, sole/foot print, thighs, tortoise' foot

Animal's tail $\ni$ \{fly whisk*, horse tail*\}

Animal's trunk $\ni$ \{hump*, thorax, scrotum, udder/dug*, nipple*, red patch*\}

Internal parts of the animal's body include the canonical organs such as:
Animal's internal parts $\ni$ \{bladder, heart, intestines, kidney, liver, lungs, small intestines, spleen $\}$

\section{Parts of a plant}

Any plant has two major canonical body sections namely the root that goes into the ground to aid in food transmission and the stem that grows upwards specifically used for photosynthesis and food transmission. Thus body parts of plant $\ni$ \{root, stem . These two major sections exhibit the following distinctive features:

Table 5: Distinctive features of body parts of plant

\begin{tabular}{|l|l|l|}
\hline & root & stem \\
\hline Functional & + & + \\
\hline Homeomerous & - & - \\
\hline Separable & + & + \\
\hline Grows underground to absorb water and minerals & + & - \\
\hline Long thin part with leaves and grows above ground & - & + \\
\hline
\end{tabular}

From the table 5 above, we gather that parts of the plant have common features such as [+functional, homeomerous, +separable]. However, distinctive features include the following: the root has [+ grows underground to absorb water and minerals] as a distinctive feature while the stem has [+ long thin part with leaves and grows above ground]. The roots contain the following sections:

Root $\ni$ \{radicle, rhizome, root stock

Stem $\ni$ \{annual ring/annulet, awn*, branch, bud, companion cell, knot/joint*, flower, leaf, leaf vein, phloem, sieve plate, sieve tube segment, stalk*, tissue, tracheids, xylem\}
Flower $\ni$ \{anther, calyx, filament, ovary, pistil, pollen, stamen, stigma, style $\}$

Leaf $\ni$ \{chlorophyll, flower*, stomata

\section{Parts of a house}

Generally we build houses so as to stay in. Otherwise when people leave there houses then the place becomes deserted. There are also small houses called huts. Basically, a house of whatever nature has various common parts that are outside, internal and also the surrounding. The house has major recognizable canonical external parts expressed as: house $\ni$ \{floor, roof, walls $\}$. The floor is also made of a foundation.

Table 6: Distinctive features of parts of a house

\begin{tabular}{|l|l|l|l|}
\hline & floor & roof & wall \\
\hline Functional & + & + & + \\
\hline Homeomerous & - & - & - \\
\hline Separable & + & + & + \\
\hline Bottom surface where people walk on & + & - & - \\
\hline Top part that covers a house & - & + & - \\
\hline Long vertical part divides or surrounds a house & - & - & + \\
\hline
\end{tabular}

The table shows the following distinctive features of parts of a house: floor [+ bottom surface where people walk on], roof [+ top part that covers a house] and wall [+ long vertical part that divides or surrounds a house]. The other common features include: [+functional, -homeomerous, +separable]. Since the house never stands in isolation without the surrounding or compound, humans have come up with various ways of naming these surroundings. In general:
House' surrounding $\ni$ \{backyard, backyard for toilets, gate, lawn, verandah $\}$

The roof of a house may or may not contain parts such as arched roof/dome*, beam, eaves, ceiling, cross beam, pinnacle or steeple, rack and rooflet among others. This is represented in the formula below:

Roof $\ni$ \{arched roof/dome*, beam, eaves, ceiling, cross beam, pinnacle/steeple, rack $^{*}$, rooflet* ${ }^{*}$ 
The wall of a house may have the following optional parts: alcove* and chimney*. However, walls of majority of the modern houses tend to possess among others the following parts:

Wall $\ni$ \{alcove*, chimney*, doors/doorway, lintel/sill, locks, nook, top of the walls, wall shelf*, windows

Interior parts of the house include optional sections that are not found in many traditional houses such as balcony*, bathroom*, dining room*, kitchen* and the toilet* ${ }^{*}$. However, in general, modern houses exhibit almost all of the above named optional parts together with other sub sections for example, bedroom, corridor and sitting room. In general, what can be found in the inner side of a house include the following:

Interior parts of a house $\ni$ \{balcony*, bathroom*, bedroom, corridor, dining room*, kitchen*, lounge, toilet*

\section{Parts of a vessel}

The vessels we are talking about include the ship, dhow and even the boat. The common vessel $\exists$ \{prow, hold, poop/stern $\}$ and these parts have distinctive features as shown on the table below:

Table 7: Distinctive features of parts of a vessel

\begin{tabular}{|l|l|l|l|}
\hline & prow & hold & poop/stern \\
\hline Anterior part of a vessel & + & - & - \\
\hline Middle part of a vessel & - & + & - \\
\hline Posterior part of a vessel & - & - & + \\
\hline
\end{tabular}

According to the table above, these three parts exhibit various features: prow [+ anterior part of a vessel], hold of a vessel [+middle part of a vessel] and poop/stern [+ posterior part of a vessel]. Though other vessels look complex, there are other minor parts that may be considered optional. Therefore, parts of a vessel both canonical and facultative are presented as:

Vessel's body $\ni\{$ anchor, ceiling/interior part of a vessel, dhow's entry, edge of a vessel, keel, outrigger, rope yard, small vessel yard, upper part of boat, vessel's cutwater, vessel's pit, vessel store, vessel toilet, vessel yard

\section{Parts of other selected objects}

There are many objects used by humans to accomplish various tasks. These objects also have parts. For example:

Bed $\ni$ \{bed's legs, headboard, rear board/footboard, under-bed space $\}$

Book $\ni$ \{chapter, cover, leaf/page
Chair $\ni$ \{chair's legs, leaning part, sitting part, under-chair space $\}$

Knife $\ni$ \{blunt edge, handle, sharp edge

Spear $\ni$ \{handle, spearhead $\}$

\section{Place-area relation}

The place - area relation shows the relationship between the place and the area. The place area relation has generally the distinctive features such as [-functional, +homeomerous, -separable] [7]. Place is a component of an area. Places which are parts within an area are not separable owing to the fact that they are natural. They cannot be functional but are homeomerous in the sense that every place in an area is similar to every other and to the whole. Under this meronymy relation, parts of the world are explained as here below:

\section{Parts of the world}

Generally, the world comprises natural things. Two broad sections of the world are basically the land and sky. Thus the world $\ni$ \{land, sky\} which exhibit distinctive features as shown in the table below:

Table 8: Distinctive features of parts of the world

\begin{tabular}{|l|l|l|}
\hline & land & sky \\
\hline Functional & - & - \\
\hline Homeomerous & - & - \\
\hline Separable & - & - \\
\hline Bottom surface of the earth & + & - \\
\hline Space above the earth & - & + \\
\hline
\end{tabular}

These parts share the following common features: [-functional, +homeomerous, -separable]. However, they differ in that the land has [+bottom surface of the earth] as a distinctive feature while the sky has [+space above the earth]. The land comprises the following two canonical sub parts as expressed as Land $\ni\{$ dry land, water mass $\}$ :

Dry land $\ni$ \{anthill, apex, arid land, bay, cemetery, continent, crater, desert, Equator, escarpment, garden, hill, hillock, lake bend land, mountain, 
North Pole, peninsula/cape, pier, plain, plateau, ports/inlets, shrub, thicket/forest, valley, wilderness

Water mass $\ni$ \{dam, deep waters, dip, drying seashore, gulf/bay, island, lake, large lake, lake shore river, marsh, pier, pond, pool, rain water trench, shallow coastal area, slip way, spring, stream, swampy place

On the other hand, the sky $\ni\{$ air, clouds, moon, planets, rainbow*, stars, wind $\}$ :

Planet $\ni$ \{Earth, Jupiter, Mars, Mercury, Neptune, Pluto, Saturn, Uranus\}

Stars $\ni$ fish shaped stars, journey star, meteor/shooting stars, pleiades/constellation, sun $\}$

Wind $\ni$ \{afternoon winds, anticyclone, breeze, cyclone, easterly wind, land breeze, north west wind, northerly winds, north south winds, one directional wind, west east winds, south north winds, sea breeze, south monsoon wind, strong wind, typhoon/hurricane, whirlwind/cyclone

\section{Period - time relation}

In the period - time relation, we look at parts of an abstract whole that are not concrete. These parts cannot be touched but can be felt through the human senses. In regards to this relation, the study analyses parts of time that is generally referred to as period but with specific names. As was indicated earlier in this work, [3] explained that meronymy ought not to be concerned only with physical or concrete objects alone but also existing amongst non-concrete entities and other abstract nominal notions. The abstract nominal notions are the ones we are referring to as parts of time. Parts of time are basically concerned with the aspect of day and night that normally have equal number of twelve hours. Thus time $\exists\{$ day, night $\}$. These parts have the following distinctive features:

Table 9: Distinctive features of time

\begin{tabular}{|l|l|l|}
\hline & day & night \\
\hline Functional & + & + \\
\hline Homeomerous & - & - \\
\hline Separable & + & + \\
\hline Time between morning and evening & + & - \\
\hline During dark from past evening till dawn & - & + \\
\hline
\end{tabular}

Both the day and night have common features such as [+functional, -homeomerous, +separable]. The day has [+time between morning and evening] and night [+during dark from past evening till dawn]. Thus, the sub parts of time are basically presented as here below:

Day $\exists$ \{evening, herd's return time, herd's setting time, late afternoon, morning, noon, sunrise/dawn, sunset $\}$

Night $\ni$ \{early morning, first cock crow, midnight, second cock crow, sunrise $\}$

\section{Colour - spectrum relation}

The colour - spectrum relation deals with the types of colours that form a band generally referred to as spectrum. Colour terms are generally abstract that means they cannot be touched. As other tangible objects exhibit distinctive features drawn from their adjectives and activities, it appears difficult to show the distinctive features of colours because of non existence of their physical reality. What is witnessed is that colours don't have physical distinctive features but tend to have objects with their natural colours used as distinctive features. Colour terms include the primary seven colours like that of rainbow. However, there are also those colours caused by mixing them generally referred to as secondary colours. The primary colour terms are indicated by the initials ROYGBIV [red, orange, yellow, green, blue, indigo and violet $]$. Thus colour $\ni\{$ blue, green, indigo, orange, red, violet. yellow $\}$. The distinctive features of colours can be shown as in the table 10 below:

Table 10: Distinctive features of Colour

\begin{tabular}{|l|l|l|l|l|l|l|l|}
\hline & red & orange & yellow & green & blue & indigo & violet \\
\hline Colour of blood & + & - & - & - & - & - & - \\
\hline Colour of ripen banana & - & + & - & - & - & - & - \\
\hline Colour of lemons or butter & - & - & + & - & - & - & - \\
\hline Colour of leaves of plants & - & - & - & + & - & - & - \\
\hline $\begin{array}{l}\text { Colour of clear sky, sea or } \\
\text { ocean }\end{array}$ & - & - & - & - & + & - & - \\
\hline Very dark blue colour & - & - & - & - & - & + & - \\
\hline Bluish purple colour & - & - & - & - & - & - & + \\
\hline
\end{tabular}


From the above table, we can gather that the following distinctive features are manifested: red [+colour of blood], orange [+ colour of ripen banana], yellow [+colour of lemons or butter], green [+colour of leaves], blue [+colour of clear sky, sea or ocean], indigo [+very dark blue colour] and violet [+bluish purple colour]. There are also secondary colours presented as:

Secondary colours $\ni$ \{black, brown, golden colour, grey, purple, white $\}$

\section{CONCLUSION}

Though there are many meronymy classifications proposed by earlier scholars such as [7, 3] for example the component - integral object, member - collection, portion - mass, stuff - object, feature activity and also place - area, there are also other meronymy classifications such as the proposed period time and colour - spectrum relations. The two proposed classifications generally deal with the meronimies of abstractions. The meronymy relation can be retrieved from lexicographical texts using the pattern-based approach such as $\left[\mathrm{NP}_{\text {mero }}\right.$ is part of $\left.\mathrm{NP}_{\text {holo }}\right]$ or $\left[\mathrm{NP}_{\text {holo }}\right.$ has $\mathrm{NP}_{\text {mero }}$ ] among others. It is very clear that meronymy analysis can also be done using the Componential Analysis theory in a table matrix and presented using the Set theory formulas.

\section{REFERENCES}

1. Montesinos, C. O. (2010). The Parts of the Building: Meronymy in the Discourse of Construction Engineering. Estudios Ingleses de la Universidad Complutense, 18, 11-34. Retrieved from

www.ucm.es/BUCM/revistas/fill/11330392/articulo s/EIUC1010110011A.PDF

2. Lyons, J. (1981). Language and Linguistics. Cambridge: Cambridge University Press.

3. Cruse, D. A. (1986). Lexical Semantics. Cambridge: Cambridge University Press.

4. Miller, A. G. (1991). The Science of Words. New York: Scientific American Library.

5. Hatch, E., \& Brown, C. (1995). Vocabulary, Semantics and Language Education. Cambridge: Cambridge University Press.

6. Prinsloo, D., Chuwa, A. R., \& Taljard, E. (2000). The Lexicons of Africa. In V. Webb, and Kembo Sure (Wh.), African voices: An introduction to language and linguistics of Africa, 220-44. Southern Africa: Oxford University Press.

7. Winston, E. M., Chaffin, R., \& Herrmann, D. (1987). A Taxonomy of Part-Whole Relations. Cognitive Science, 11, 417-444. Retrieved from www.Csjarchive.cogsci.rpi.edu/1987V11/04/p0417 p0444/MAIN.PDF

8. Fromkin, V., Rodman, R., \& Hyams, N. (2007). An Introduction to Language. Boston: Thomson Wadsworth.
9. Cruse, D. A. (2002). Notes on Meaning in Language. Retrieved from www.dooku.miun.se/engelska/englishDLing/Sema ntics/Summary of Cruse.pdf

10. Wierzbicka, A. (1988). The Semantics of Grammar. Amsterdam: John Benjamin's Publishing Co.

11. Weller, K., \& Stock, W. G. (2008). Transitive Meronymy. Automatic Concept-based Query Expansion using Weighted Transitive Part-whole Relations. Retrieved from www.philfak.uni_duesseldorf.de/fileadmin/Redakti on/institute/Informationswissenschaft/stock/120937 8039transitive.pdf

12. Gharagozloo, N. (2012). Meronymy in Persian: Cognitive Linguistics Perspective. Middle-East Journal of Scientific Research, 11 (11), 1595-1601. Retrieved from DOI: 10.5829/idosi.mejsr.2012.11.11.470

13. Jensen, K. E. (2008). Translation and Translation Theory. Lecture Notes, Week 1(36). University of Aalborg. Retrieved from www.hum.aau.dk/ OT08/OTLNI.pdf

14. Saeed, J. (2009). Semantics ( $3^{\text {rd }}$ ed.). United Kingdom: Wiley Blackwell.

15. Katz, J. J., \& Fodor, J. A. (1963). The Structure of the Semantic Theory. Retrieved from www.slashdocs.com/irvih/week-1-Katz-j-j-fodor-ja-1963-the-structure-of-semantic-theory-html

16. Katz, J. J., \& Fodor, J. A. (1981). Language and other Abstract Objects. Totowa: N. J. Rowman and Littlefield.

17. Bussmann, H. (1996). Routledge Dictionary of Language and Linguistics. London: Rout ledge.

18. Goodenough, W. H. (1956). Componential Analysis and the Study of Meaning. Language, 32 (1), 195-216. Retrieved from http://www.anthro.ucsd.edu/ jhaviland/LanguageC ulture/READINGS/Goodenough/KinshipLanguage. 1956.pdf

19. Lounsbury, F. G. (1963). The Structural Analysis of Kinship Semantics. Proceedings of the Ninth International Congress of Linguists, 1073-93. The Hague: Mouton. Retrieved from www.citeseerx.ist.psu.edu/showciting?cid $=203300$ 8

20. Hjelmslev, L. (1970). Language: An Introduction. Madison: The University of Wisconsin Press.

21. Bruck, T. V. D. (2010). Meronymy Extraction Using an Automated Theorem Prover. Retrieved from www.jlcl.org/2010_Heft1/tim_vorderbruk.pdf

22. Enderton, H. B. (1977). Elements of Set Theory. New York: Academic Press. Retrieved from www.math.ucla.edu hbe/ency.pdf

23. Borschev, V., \& Partee, B. (2001). Lecture 1. Basic Concepts of Set Theory. Ling 726: Mathematical Linguistics, September 6, 1-6. Retrieved from http://www.people.umiss.edu/Partee/726_01/lectur e/lecture1.pdf 
24. Stephan, F. (2009). Set Theory. Retrieved from www.compo.nus.edu.sg/ fstephan/settheory.pdf

25. Bonissone, P. P. (1980). A Fuzzy Sets Based Linguistic Approach: Theory and Applications. Proceedings of the 1980 Winter Simulation Conference, 99-111. Retrieved from www.people.vcu.edu/ 1parker/DBGroup/Reference s/Theory.pdf the 1980

26. Chen, R. (1999). The Categorization and Taxonomy of Scientific Theories. $11^{\text {th }}$ International Congress of Logic, Methodology and Philosophy of Science. Retrieved from www.scu.edu.tw/Philos/Index/teacher/Chen/Micros oftword-Categorization and Taxonomy.pdf

27. Benz, A., Jager, G., \& van Rooij, R. (2007). An Introduction to Game Theory for Linguists. Retrieved from http://www.web.mit.edu/linguistics/events/iap07/B enz-Jager-vanRooy.pdf

28. Weiss, W. A. R. (2008). An Introduction to Set Theory. Retrieved from http://www.math.toronto.edu/weiss/Set_Theory.pdf

29. Roitman, J. (2011). Introduction to Set Theory. Retrieved from www.math.ku.edu/ roitman/Stb3fullWeb.pdf

30. Hornby, A. S. (Ed.) (2010). Oxford Advanced Learner's Dictionary. ( $8^{\text {th }}$ ed.). Oxford: Oxford University Press.

31. Klein, H. E. M. (2000). Meronymy or Part-whole Relations in Indigenous Languages of Lowland South America. In Hein van der Voort \& Simon van de Kerke (eds.), Indigenous Languages of Lowland South America [Indigenous Languages of Latin America] 1, 83-98. 